\title{
Desigualdades Salariais de Gênero no Primeiro Emprego, Reemprego e Remanescentes nos Setores Econômicos: Evidências para o Sul do Brasil
}

\section{Gender Wages Differences in First Jobs, Reemployment and Remaining in Economic Sectors: Evidences for Southern Brazil}

\author{
Magno Rogério Gomes* \\ Solange de Cássia Inforzato de Souza* *
}

\begin{abstract}
Resumo: Este artigo tem por objetivo analisar as evidências das desigualdades salariais de gênero segundo os setores econômicos e as classes de emprego na região sul do Brasil. A partir dos dados da Relação Anual de Informações Sociais de 2013, do Ministério do Trabalho e Emprego, aplicou-se a decomposição salarial de OaxacaBlinder. Os resultados encontrados na região comprovam a prática discriminatória de salários contra as mulheres, mesmo no setor de serviços, em que a absorção ocupacional das mulheres é maior. $\mathrm{Na}$ agricultura e na indústria, as mulheres são discriminadas duplamente, tanto na inserção ocupacional quanto nos salários, agravando-se no setor industrial. Os dados favoráveis às mulheres estão no setor de comércio e na contratação do primeiro emprego, contrariamente às mulheres inseridas de forma remanescente no mercado de trabalho na região sul do país, cujas evidências são pouco exploradas na literatura brasileira.
\end{abstract}

Palavras-chave: Diferenças salariais de gênero. Classes de emprego. Setores econômicos.

\begin{abstract}
This study aims to analyze the gender wages gap according as economic sectors and job classes in Southern Brazil. From the data of the Annual Social Information Relationship 2013 of the Ministry of Labor and Employment, we applied the decomposition of Oaxaca-Blinder from the RAIS 2013 - Social Information Annual - the Ministry of Labor and Employment. The results for this region showed there is wage discrimination against women, even in the Services sector where occupational absorption of women is higher. For the Agriculture and Industry women are discriminated twice, both in occupational insertion as in wages, worsening in the industrial sector. The favorable data for women are in the trade sector and the hiring of first job, unlike inserted remaining way in the labor market in Southern region whose evidences are underexplored in Brazilian literature.
\end{abstract}

Keywords: Gender wages gap. Jobs classes. Economic sectors.

JEL Classification: J31; J71.

* $\quad$ Mestre em Economia Regional pela Universidade Estadual de Londrina (UEL). Professor da Universidade Estadual de Londrina e da Universidade Norte do Paraná (Unopar). E-mail: magnorg86@gmail.com

** Doutora em Educação: história, política, sociedade. Professora do curso de Economia e do Programa de Mestrado em Economia Regional da Universidade Estadual de Londrina (UEL). E-mail: solangecassia@uol.com.br 


\section{1 lntrodução}

As desigualdades e a discriminação salarial no mercado de trabalho tem sido tema relevante de estudos científicos, especialmente no Brasil, cujos contornos atuais remetem para os processos históricos de constituição e formação do mercado de trabalho e para os desníveis regionais econômicos e sociais que ainda permanecem no país.

A teoria econômica disponibiliza as explicações para as desigualdades salariais, resumidas na teoria do capital humano (SCHULTZ, 1961; BECKER, 1962, 1966, 1975; ARROW, 1971), na teoria da segmentação (DOERINGER; PIORE, 1970; VIETORISZ; HARRISON, 1973; CACCIAMALI, 1978; LIMA, 1980), na teoria da discriminação estatística (PHELPS, 1972; DICKINSON; OAXACA, 2006) e na teoria da discriminação (OAXACA, 1973; BLINDER, 1973; LOUREIRO, 2003).

De acordo com a teoria do capital humano, a produtividade e os rendimentos de um trabalhador aumentam em função da elevação da escolaridade e de suas habilidades adquiridas com a experiência, associando as desigualdades salariais à oferta de trabalho. Por outro lado, expoentes da teoria da segmentação defendem a relevância da demanda de trabalho para a elucidação das diferenças nos salários. Tais desigualdades também podem ser explicadas pela discriminação de gênero e cor: dadas as características produtivas dos indivíduos, e na ausência de salários compensatórios, a persistência dos hiatos salariais é atribuída pela discriminação, argumenta Becker (1966, 1975).

No Brasil, estudos empíricos confirmam a diferenciação de salários no mercado de trabalho entre homens e mulheres, assim como entre brancos e não brancos para o país e suas regiões (CACCIAMALI; HIRATA, 2005; SALVATO et al., 2008; CACCIAMALI; TATEI; ROSALINO, 2009; CUGINI et al., 2014; FIUZA-MOURA, 2015; SOUZA; GOMES, 2015; PEREIRA; OLIVEIRA, 2016). Regionalmente, o sul do Brasil revela significativas diferenças nos rendimentos das mulheres e homens, mas há uma lacuna nas pesquisas acerca das diferenças salariais segundo os setores econômicos e as classes de emprego: primeiro emprego, reemprego e remanescentes. Uma vez identificadas as fontes das desigualdades salariais na região, as intervenções de políticas públicas direcionadas ao mercado de trabalho podem tornar-se mais eficazes.

Diante disso, este artigo tem por objetivo analisar as desigualdades salariais por gênero nos setores e classes de emprego (primeiro emprego, reemprego e remanescentes no mercado de trabalho) na região sul do Brasil. A partir da base de dados da Relação Anual de Informações Sociais (RAIS) de 2013 (BRASIL, 2015), foram estimadas as equações salariais e realizada a decomposição salarial de Oaxaca-Blinder adaptada para esta pesquisa. 
A hipótese levantada é de que as diferenças e a discriminação de salários sejam maiores em setores nos quais os trabalhadores já são segregados no momento da inserção, e também para a classe dos remanescentes, e menores nas classes do primeiro emprego e reemprego, pois nestas as diferenças de salários e a discriminação estão ausentes dos bônus referentes à habilidade, responsabilidade, promoções e bonificações por tempo de serviço, negociações, entre outros.

Este artigo está organizado em cinco seções, além desta introdução: a segunda aborda as teorias econômicas e o referencial empírico das diferenças salariais; a terceira expõe a metodologia empregada e a base de dados utilizada; a quarta mostra as características do trabalhador da região estudada; a quinta discute os resultados da determinação de salários e da decomposição salarial de sexo; e a sexta apresenta as considerações finais do trabalho.

\section{Estabelecimentos Teóricos e Evidências Empíricas sobre Diferenças Sala- riais}

Teoricamente, as desigualdades salariais são atribuídas às dotações produtivas dos indivíduos, à segmentação dos postos de trabalho e à discriminação. No primeiro caso, a partir da teoria do capital humano, Mincer $(1958,1974)$ justifica essas diferenças salariais pelas diferenças dos fatores produtivos dos indivíduos, como escolaridade e experiência.

$\mathrm{Na}$ teoria da segmentação, a necessidade de ajustes alocativos, a estrutura industrial, a tecnologia e o processo histórico e de lutas de classes são reveladores das diferenças de salários. Doeringer e Piore, expoentes na teoria da segmentação, defendem o ajuste alocativo como principal determinante da segmentação (LIMA, 1980). Para eles, são as características pessoais dos indivíduos que determinam o tipo de mercado em que serão inseridos.

Para Vietorisz e Harrison (1973), a segmentação surge em virtude das diferenças tecnológicas existentes entre as atividades econômicas, pois as inovações tecnológicas incentivam a qualificação da mão de obra e geram aumento da produtividade e dos rendimentos dos trabalhadores. Michael Reich et al. (apud LIMA, 1980) mostram que as desigualdades salariais resultam de um processo histórico e da existência de diferentes classes sociais, que acabam por ocasionar a segmentação do mercado de trabalho.

No Brasil, Cacciamali (1978) sustenta a sua pesquisa na teoria da segmentação e identifica certas características da mão de obra que preencherão os postos de trabalho, como status socioeconômico, idade, escolaridade, sexo e experiência. Homens de maior escolaridade, experiência profissional e status socioeconômico obterão os melhores empregos no segmento primário, e os indivíduos, homens e mulheres, menos favorecidos da sociedade desempenharão suas atividades no 
secundário. Casari (2012) confirma a segmentação pelos setores de atividade, pelas ocupações e pela filiação a sindicatos, que impactam sobre os rendimentos e alocação dos trabalhadores.

Por fim, as diferenças salariais podem ser explicadas pela discriminação de gênero e cor. Para Becker (1966, 1975), existe discriminação econômica contra membros de um grupo sempre que os salários pagos sejam menores, já descontadas as diferenças pelas habilidades individuais. Arrow (1971) completa que a discriminação ocorre quando as características individuais dos empregados não relacionadas à produtividade também são valoradas no mercado de trabalho, como raça, etnia e gênero.

Loureiro (2003) define a economia da discriminação como o tratamento desigual quando os indivíduos são avaliados em critérios irrelevantes para a atividade envolvida, sendo a discriminação no mercado de trabalho a que mais se destaca na literatura. A existência de discriminação econômica no mercado de trabalho ocorre quando determinado grupo tem habilidades, educação, treinamento, experiência e produtividade iguais, porém recebe salários diferentes ou tem algum tratamento diferenciado por causa da cor da pele, sexo, religião, idioma, condição econômica e social, aparência física e etnia, ainda que essas características não tenham qualquer efeito sobre a sua produtividade.

Loureiro (2003) classifica a discriminação no mercado de trabalho em: a) discriminação salarial, que ocorre quando trabalhadores do sexo feminino (negros) recebem salários menores do que trabalhadores do sexo masculino (brancos) que fazem o mesmo trabalho; b) discriminação de emprego, quando mulheres e negros, por exemplo, ficam em desvantagem no que tange à oferta de emprego, sendo, assim, os mais atingidos pelo desemprego; c) discriminação de trabalho ou ocupacional, quando mulheres (negras) são arbitrariamente restringidas de ocupar certas ocupações, mesmo apresentando as mesmas capacidades dos homens (brancos); e d) discriminação oriunda das oportunidades desiguais no acesso à educação formal ou treinamento no trabalho.

Segundo Becker (1957 apud LOUREIRO, 2003), a discriminação pode ser provocada pelo empregador, pelo cliente e pelo empregado, além da discriminação estatística. Na discriminação do empregador, o contratante que discrimina está disposto a abrir mão de seus lucros para satisfazer a sua preferência pela discriminação. Dado o salário de mercado, os empregadores que discriminam irão preferir contratar homens em vez de mulheres e estariam dispostos a contratar indivíduos do sexo feminino apenas se forem por um salário menor do que o de mercado. A diferença é o preço da discriminação. Quanto maior o preconceito, maior será o coeficiente da discriminação e maiores serão as diferenças na contratação (absorção) e nos rendimentos. 
O preconceito por parte do cliente é outra forma de preconceito pessoal que alimenta a discriminação - a discriminação do cliente. Por exemplo: os clientes preferem ser atendidos por homens brancos em vez de mulheres ou minorias. Se os clientes discriminam dadas as suas preferências, sua decisão de compra não se baseia no preço do produto, mas nos preços ajustados pela utilidade, e sendo $p$ o preço de mercado, o cliente que discrimina perceberá o preço como $p(1+d)$. No exemplo, se as pessoas não gostam de ser atendidas (comprar) por mulheres ou minorias, a demanda por esses serviços ou produtos reduzirá, obrigando os empresários que contratam essa mão de obra a baixarem os preços, compensando, assim, a discriminação $(d)$. Essa forma de discriminação acaba por gerar postos de trabalhos segregados, pois os trabalhadores não discriminados irão preencher posições mais sensiveis (ocupações que interagem com clientes e remuneram melhor) das empresas e os funcionários discriminados serão alocados em posições que não comprometam diretamente a lucratividade das firmas.

$\mathrm{Na}$ discriminação do empregado, o preconceito pessoal (discriminação) está entre os trabalhadores. Nesse caso, homens brancos podem evitar situações que tenham que interagir com as mulheres e minorias. Mesmo que não haja preconceito por parte do empregador, o mesmo tem que pagar um prêmio (salários maiores) para esses funcionários se submeterem a tal interação. Portanto, para que essas empresas tenham o mesmo lucro das demais, mulheres e minorias teriam que se sujeitarem a um salário menor. Uma forma que as empresas encontram para acomodar essa discriminação é a segregação, de forma que os empregados oriundos de demografias diferentes não tenham que interagir. Os empregadores contratam apenas homens, brancos ou outras maiorias, para funções específicas, ainda que membros de sexo oposto ou etnia diferente tenham o potencial de desempenhar a mesma função.

Na literatura teórica, Phelps (1972) destaca, ainda, a discriminação estatística oriunda do problema das informações imperfeitas do mercado sobre a produtividade e o potencial do empregado. Nesse caso, o indivíduo é valorado tendo como base a média do grupo a que pertence. Essa discriminação, de acordo com Loureiro (2003), pode ser atribuída como parte do problema de seleção, quando as características observadas (educação, treinamento, experiência, etc.) não constituem fatores perfeitos de previsão de produtividade, fazendo com que os empresários utilizem dados do grupo para a tomada de decisão.

Na literatura empírica, Francine e Kahn (2000) estudam a evolução do hiato salarial e a discriminação nos Estados Unidos para os anos de 1978, 1988 e 1998 e mostram que houve uma redução nas diferenças salariais entre os gêneros. Entretanto, as mulheres continuariam sendo discriminadas no mercado de trabalho, embora em menor proporção. Parte dessas disparidades salariais remanescentes estaria ligada à divisão sexual do trabalho no lar, tanto diretamente através de seu 
efeito sobre a fixação da força de trabalho das mulheres, quanto indiretamente pelo impacto da discriminação estatística contra as mulheres.

De acordo com Chahad (1986), os diferentes níveis de escolaridade entre as classes trabalhadoras representam o maior fator determinante das discrepâncias salariais no Brasil. No entanto, fatores como idade, setor de atividade, região de residência e gênero também contribuem para a determinação e diferenças do rendimento do trabalho assalariado. Cacciamali e Hirata (2005) expõem que a discriminação contra a mulher é maior nos cargos com salários elevados e que a situação se agrava para as mulheres negras.

Outra possível explicação para o hiato salarial entre homens e mulheres é o poder de negociação dos salários que cada grupo dispõe. As mulheres são em geral menos propensas a iniciar uma negociação almejando um aumento salarial. "Nice girls don't ask" (boas garotas não perguntam) é a hipótese de Babcock e Laschever (2003).

Em Portugal, pesquisadores utilizaram dados longitudinais dos salários para homens em mulheres, de 2002 a 2009, combinados a informações dos empregadores e mensuraram o poder de negociação relativo e impacto no hiato salarial dos gêneros. Concluíram que de 10\% a 15\% da defasagem salarial entre os gêneros podem ser atribuídos à ação de negociação inferior do sexo feminino. As mulheres são menos propensas a iniciar a negociação e são (muitas vezes) negociadoras menos eficazes do que os homens (CARD; CARDOSO; KLINE, 2013).

Embora alguma diferença salarial possa ser decorrente do fato de as mulheres evitarem a negociação, ainda assim existe um hiato salarial a favor dos homens quando controladas as características individuais dos trabalhadores. Estudos empíricos comprovam o fato, como os descritos a seguir.

Oaxaca (1973) e Blinder (1973) desenvolvem um método de decomposição de diferenças salariais utilizando as equações de determinação de salários de homens e mulheres na região urbana dos Estados Unidos em 1967 e ambos concluem que, mantidas as características produtivas, homens e brancos ganhavam mais do que as mulheres e os não brancos.

No Brasil, há ensaios sobre discriminação salarial que fizeram uso da decomposição de Oaxaca (1973) e Blinder (1973). Salvato et al. (2008) medem a discriminação nos estados da Bahia e Minas Gerais no ano de 2005 e confirmam que em maiores faixas de renda há maior discriminação, sendo mais significativa a discriminação de gênero, com maior peso para homens brancos contra mulheres negras. Encontraram também um efeito discriminação maior para os negros no estado da Bahia na comparação com Minas Gerais.

Cugini et al. (2014) mensuram a discriminação salarial dos gêneros entre os anos de 2002 e 2011 no Brasil, com os dados da Pesquisa Nacional por Amostra de Domicílio (PNAD), e constatam o aumento da participação da mulher no mercado 
de trabalho. No entanto, apesar de uma redução das diferenças de salários entre homem e mulher, houve um aumento da discriminação contra as mulheres. Fiuza-Moura (2015), no estudo das diferenças salariais na indústria brasileira por sexo, cor e intensidade tecnológica, usa os dados da PNAD 2012 e mostra elevado grau de discriminação salarial entre os gêneros, principalmente em relação às mulheres não brancas, sendo menor quando observados segmentos mais intensivos em tecnologia.

Ainda que pouco explorados, os estudos sobre o primeiro emprego e reemprego, como os de Gonçalves e Monte $(2008,2011)$ para o mercado de trabalho formal no nordeste do Brasil, concluem que o baixo percentual de inserção dos jovens entre 16 e 24 anos no mercado de trabalho formal pode ser atribuído a pouca experiência, que reflete tanto na probabilidade de inserção quanto na remuneração. Os trabalhadores que procuram por um primeiro emprego apesar de ter, por vezes, mais escolaridade (educação formal) que os trabalhadores mais velhos, acabam se inserindo em ocupações de conhecimento ínfimo, e os trabalhadores com experiência (mais velhos) possuem maior facilidade de inserção em atividades de maior produtividade e rendimentos.

Monte, Araújo e Lima (2007) acrescentam, com dados da Pesquisa Mensal de Emprego (PME) de 2000 e 2001, que indivíduos que estão em busca de um reemprego no mercado formal tiveram mais chances de serem contratados em comparação com os indivíduos que buscaram o primeiro emprego e que o hiato salarial foi relativamente elevado a favor dos indivíduos reempregados. Reis (2015) também revela que a escolaridade é uma variável que aumenta a probabilidade de o indivíduo encontrar um primeiro emprego. Contudo, indivíduos com experiência têm maior probabilidade de ser reempregados, mesmo tendo escolaridade inferior aos que buscam a sua primeira ocupação.

No que se refere ao gênero, Gonçalves e Monte (2008, 2011) observam que as preferências pró-homem são menores entre os indivíduos que buscam o primeiro emprego do que entre os indivíduos do reemprego no nordeste brasileiro, e a remuneração média das mulheres são similares às dos homens no primeiro emprego. Outros pontos importantes destacados pelos autores foram: ter maior escolaridade aumenta a probabilidade de contratação via primeiro emprego; as pequenas empresas destacam-se por absorver a maior parte dos trabalhadores, pagarem menores salários e exigirem pouca qualificação; já as empresas de médio e grande porte exigem um profissional mais qualificado e suas remunerações são superiores às pagas pelas pequenas empresas.

Nos anos recentes, portanto, estudos empíricos confirmaram a diferenciação de salários no mercado de trabalho entre homens e mulheres e manifestaram a discriminação tanto de gênero quanto de cor. Este trabalho objetiva preencher uma lacuna nas pesquisas para o mercado de trabalho do sul do Brasil, na busca 
da medida dos fatores que explicam as desigualdades de salários, especialmente dos trabalhadores formais nos setores e nas classes de emprego.

\section{Metodologia}

Nesta seção são apresentadas a base de dados, a operacionalização das variáveis e a estratégia empírica da investigação científica.

\subsection{Base dos Dados}

Para a realização deste estudo, são utilizados os microdados da RAIS do Ministério do trabalho de 2013 (BRASIL, 2015) ${ }^{1}$ para a região sul do Brasil. Dessa base de dados, foram extraídos apenas os indivíduos com mais de 15 anos e que mantinham vínculo empregatício em 31 de dezembro de 2013, considerados os que ingressaram no primeiro emprego, os que foram reempregados no ano de 2013 e os remanescentes de anos anteriores.

Os trabalhadores foram classificados conforme a escolaridade em: baixa instrução (indivíduos com escolaridade igual ou inferior ao ensino fundamental incompleto), fundamental (com escolaridade igual ao fundamental completo ou ensino médio incompleto), ensino médio (com ensino médio completo ou com graduação incompleta) e superior (escolaridade igual ou maior do que a graduação completa). Separaram-se também os indivíduos segundo a cor da pele: brancos (indivíduos de cor de pele branca ou amarela) e não brancos (pardos e os pretos).

A construção das variáveis referentes às ocupações baseou-se na Classificação Brasileira de Ocupações (CBO), criada em 2002 e atualizada em 23 de agosto de 2004. Elas sofreram adaptação metodológica nesta pesquisa, sendo organizadas em quatro grandes grupos: dirigentes (diretores e gerentes), profissionais das ciências e das artes (PCA), profissionais de nível técnico e operacionais (agrícolas e trabalhadores na produção). Para os setores econômicos, utilizou-se a Classificação Nacional de Atividade Econômica (CNAE 1.0, revisada em 2002), cujo agrupamento se fez em quatros grandes setores econômicos, segundo a metodologia do IBGE: agrícola, comércio, serviços e indústria.

No que se refere ao porte das empresas, seguiu-se o critério do Sebrae por número de empregados. Para o setor da indústria, classifica-se como: microempresa (até 19 ocupados); pequena empresa (de 20 a 99 ocupados); média empresa

$1 \quad$ A Rais 2013 é a base de dados mais atual disponibilizada pelo Ministério do Trabalho e Emprego na ocasião da pesquisa. Trata-se de uma pesquisa por registro administrativo, de âmbito nacional, com periodicidade anual, e é de declaração obrigatória para todos os estabelecimentos. Ela processa informações sociais relativas aos vínculos empregatícios formais, que visa gerar estatísticas sobre o mercado de trabalho formal a ser utilizadas na elaboração, monitoramento e implementação de políticas públicas de trabalho, emprego e renda, entre outros. 
(de 100 a 499 ocupados); e grande empresa (500 ou mais ocupados). Para o setor de serviços e comércio: microempresa (até 9 ocupados); pequena empresa (de 10 a 49 ocupados); média empresa (de 50 a 99 ocupados); grande empresa (100 ou mais ocupados). E na categoria outras, quando não se enquadrar em nenhum desses requisitos.

\subsection{Decomposição do Diferencial de Salários}

Para a medida das diferenças salariais entre os gêneros, utilizando-se a decomposição de Oaxaca-Blinder adaptada para esta pesquisa, identificaram-se as variáveis associadas às características produtivas (escolaridade e experiência) e inatas (sexo e raça) e aos postos de trabalho (ocupação, setores e porte das empresas), determinantes dos salários dos trabalhadores no mercado privado formal brasileiro em 2013.

Para o presente estudo, os grupos analisados são compostos por indivíduos que ingressaram no primeiro emprego, indivíduos que foram reempregados no ano de 2013 e indivíduos remanescentes de anos anteriores, todos com vínculo em 31 de dezembro de 2013, sendo subdivididos pelos setores econômicos nos quais foram contratados.

A decomposição partiu das equações funcionais, que podem ser expressas formalmente por:

$$
\begin{gathered}
\operatorname{Ln}\left(w_{h i}\right)=\beta_{0}+C H_{i}^{\prime} \beta+\operatorname{Set}_{i}^{\prime} \theta+\operatorname{Ocup}_{i}^{\prime} \gamma+U F_{i}^{\prime} \delta+P E_{i}^{\prime} \sigma+\operatorname{Cinat}_{i}^{\prime} \varepsilon+u_{i} \\
\forall \mathrm{i} \in \mathrm{N}: \mathrm{i} \geq 1
\end{gathered}
$$

em que $\operatorname{Ln}\left(w_{h i}\right)$ é o logaritmo natural (logaritmo neperiano) do salário hora dos trabalhadores e $\mathrm{CH}_{i}$ é o vetor das variáveis que compõe o capital humano, escolaridade e experiência. A variável escolaridade foi expressa por níveis educacionais: baixa instrução, ensino fundamental, ensino médio e ensino superior. Para a variável experiência, utilizou-se a proxy (idade - anos de estudo - 5) apenas para os reempregados e remanescentes. Para os indivíduos do primeiro emprego, considerou-se zero ano de experiência. $S t_{i}$ é o vetor das variáveis dummies para os setores de atividade, indústria, comércio, serviços e agrícola. Ocup ${ }_{i}$ representa as dummies para as ocupações de cada indivíduo, ou seja, dirigentes, profissionais das ciências e das artes (PCAs), técnicos e operacionais. O vetor $U F_{i}$ constitui as dummies para as unidades federativas da região estudada. $P E_{i}$ é formado pelas variáveis dummies referentes ao porte da empresa: micro, pequena, média e grande e outras, seguindo o critério do Sebrae por número de empregados. Por fim, em Cinat $_{i}$ estão contidas as variáveis inatas de cada indivíduo, dummies para gê- 
nero e cor. As equações mincerianas foram calculadas para homens e mulheres referentes a cada setor econômico.

Neste estudo, optou-se por não utilizar o procedimento de Heckman² (correção de viés de seleção), em virtude de não corroborar as hipóteses do modelo e, principalmente, pela indisponibilidade de dados necessários para a utilização do método. Ou seja, a Rais 2013, base de dados do emprego privado formal para a demanda do trabalho, não disponibiliza algumas características intrínsecas aos gêneros e às estruturas familiares que afetam principalmente a oferta de trabalho.

O método da decomposição salarial de Oaxaca-Blinder consiste em desagregar as diferenças salariais provocadas pelas dotações produtivas, pelas características dos postos de trabalho e pelas diferenças atribuídas às valorações diferentes para as mesmas dotações, descritas como "parte não explicada". O efeito proveniente da parte não explicada foi considerado como proxy das diferenças atribuídas à discriminação salarial.

Apesar de conhecidas as limitações da metodologia, pois não é possível desagregar os prós e contras das características não observáveis dos trabalhadores que podem influenciar na discriminação pura, como criatividade e habilidades individuais, essa metodologia tem sido usada no Brasil por muitos pesquisadores. Esses estudos confirmam a robustez da metodologia, uma vez que os resultados encontrados convergem para resultados similares e corroboram a teoria econômica.

O modelo para este estudo segue Oaxaca (1973) e Blinder (1973), mas incorpora a existência do salário mínimo, que por lei exige que todas as empresas brasileiras paguem um salário mínimo independente do gênero e da cor do indivíduo. ${ }^{3}$

Assim, o Decreto $n^{0} 7.872$, de dezembro de 2012, estabeleceu que, a partir de $1^{\circ}$ de janeiro de 2013 , o salário mínimo seria de $\mathrm{R} \$ 678,00$, com um valor diário de $R$ \$22,60 e o valor/hora de $R$ \$3,08. Nesse caso, as equações de determinação de salário têm características de equações concorrentes. As origens das retas, ou a constante das regressões, são iguais, pois, independente de gênero ou cor, um indivíduo que se inicia no mercado de trabalho formal por lei não pode receber menos do que o salário mínimo. As diferenças entre a decomposição de Oaxaca-Blinder e a decomposição utilizada nesta pesquisa é a exclusão da constante das regressões. $\beta_{0}^{H}=\beta_{0}^{M}$, assim $\left(\beta_{0}^{H}-\beta_{0}^{M}\right)=0$.

$2 \quad$ O procedimento de Heckman (correção do viés de seleção) não foi aplicado neste estudo. Ao considerar a base de dados (RAIS/2013), utilizada nesta pesquisa, inviabiliza-se o uso do procedimento de Heckman, pelo fato da RAIS não disponibilizar os dados sobre os trabalhadores desocupados e a PEA. O procedimento de Heckman considera haver viés de seleção amostral quando alguns indivíduos optam por não ingressar no mercado de trabalho devido ao salário médio ofertado se encontrar abaixo de seu salário reserva.

3 Segundo a Constituição Federal de 1988 no Art. $7^{\circ}$ e inciso IV, “ são direitos de todos os trabalhadores o salário mínimo, fixado por lei, nacionalmente unificado, capaz de atender suas necessidades [...]". Ainda no Art.7, inciso XXX, é proibida a diferença de salários, de exercício de funções e de critério de admissão por motivo de sexo, idade, cor ou estado civil. 
Portanto, partindo-se das equações salariais de Mincer (1974), tem-se:

$$
\begin{aligned}
& \ln \left(w_{h}^{H}\right)=\beta_{0}^{H}+\sum_{j=1}^{n} \beta_{j}^{H} X_{j i}^{H}+u_{i}^{H} \\
& \ln \left(w_{h}^{M}\right)=\beta_{0}^{M}+\sum_{j=1}^{n} \beta_{j}^{M} X_{j i}^{M}+u_{i}^{M}
\end{aligned}
$$

em que $\ln \left(w_{h}^{M}\right)$ é o logaritmo natural do salário hora das mulheres e $\ln \left(w_{h}^{H}\right)$ é o logaritmo natural do salário/hora dos homens.

Para o mercado de trabalho formal brasileiro, as equações de determinação de salário têm características de regressões concorrentes (GUJARATI, 2006; GREENE, 2012):

$$
\beta_{0}^{H}=\beta_{0}^{M}=\beta_{0}^{J}
$$

Reescrevendo-se as equações 2 e 3, têm-se:

$$
\begin{aligned}
& \ln \left(w_{h}^{H}\right)=\beta_{0}^{j}+\sum_{j=1}^{n} \beta_{j}^{H} X_{j i}^{H}+u_{i}^{H} \\
& \ln \left(w_{h}^{M}\right)=\beta_{0}^{j}+\sum_{j=1}^{n} \beta_{j}^{M} X_{j i}^{M}+u_{i}^{M}
\end{aligned}
$$

Subtraindo-se, tem-se:

$$
\ln \left(w_{h}^{H}\right)-\ln \left(w_{h}^{M}\right)=\left(\beta_{0}^{j}-\beta_{0}^{j}\right)+\sum_{j} \beta_{j}^{H}\left(\bar{X}_{j}^{H}-\bar{X}_{j}^{M}\right)+\sum_{j} \bar{X}_{j}^{M}\left(\beta_{j}^{H}-\beta_{j}^{M}\right)
$$

Como na equação (7) $\beta_{0}^{j}=\beta_{0}^{j} \operatorname{logo}$

$$
\left(\beta_{0}^{j}-\beta_{0}^{j}\right)=0
$$




$$
\ln \left(w_{h}^{H}\right)-\ln \left(w_{h}^{M}\right)=\sum_{j} \beta_{j}^{H}\left(\bar{X}_{j}^{H}-\bar{X}_{j}^{M}\right)+\sum_{j} \bar{X}_{j}^{M}\left(\beta_{j}^{H}-\beta_{j}^{M}\right)
$$

Em que $\sum \beta_{j}^{H}\left(\bar{X}_{j}^{H}-\bar{X}_{j}^{M}\right)$ representa a parcela do diferencial atribuído às diferenças de dotações e outras características e $\sum \bar{X}_{j}^{\mu}\left(\beta_{j}^{H}-\beta_{j}^{M}\right)$ representa a parcela do diferencial de salários atribuído às diferenças de coeficientes (discriminação), ${ }^{4}$ que indica que há valoração diferente para os grupos com as mesmas dotações dos indivíduos.

\section{Perfis Produtivos e Não Produtivos dos Trabalhadores no Sul do Brasil}

As características dos empregados formais da região em estudo estão dispostas na Tabela 1, a partir das quais observa-se que a média de idade e a experiência dos homens são superiores às das mulheres e a média dos anos de estudos é superior para as mulheres na região sul do Brasil. Além disso, o maior percentual de trabalhadores é de cor branca e, mensalmente, os homens apresentam salários e jornada de trabalho superiores aos das mulheres. Ao ponderar os salários pela jornada de trabalho (o salário/hora), ainda se constata que, apesar da menor diferença, são favoráveis aos homens. ${ }^{5}$

Tabela 1 - Perfil dos trabalhadores formais do setor privado da região sul do Brasil (2013)

\begin{tabular}{lccc}
\hline \multicolumn{1}{c}{ Variáveis } & \multicolumn{3}{c}{ Sul } \\
\cline { 2 - 4 } & Homens & Mulheres & Geral \\
\hline Idade (média) & 35,0 & 33,6 & 34,4 \\
Experiência (média) & 19,1 & 16,9 & 18,17 \\
Anos de estudo (média) & 10,5 & 11,2 & 10,80 \\
Brancos (\%) & 88 & 90 & 89 \\
Não brancos (\%) & 12 & 10 & 11 \\
Salário mensal (média) & $1.909,71$ & $1.406,32$ & $1.700,23$ \\
Horas trabalho/semana (média) & 42,6 & 41,1 & 41,9 \\
Salário/hora (média) & 11,14 & 8,87 & 10,20 \\
\hline
\end{tabular}

Fonte: Elaboração própria a partir dos microdados da Rais 2013 (BRASIL, 2015).

$4 \quad$ A decomposição sugerida não incorre no problema de identificação: invariância dos resultados da decomposição frente à escolha arbitrária das variáveis a serem omitidas nos conjuntos de variáveis categóricas utilizadas nas regressões de determinação de salários. Para a correção desse problema, quando se faz uso da decomposição original, utiliza-se o processo de normalização proposto por Yun $(2003,2005)$.

5 As características produtivas e não produtivas dos trabalhadores estão esclarecidas na seção de metodologia. 
Na região sul, pouco mais de $5 \%$ dos mais de 6,7 milhões de trabalhadores formais eram de indivíduos que obtiveram o primeiro emprego em 2013. Já $33,57 \%$ corresponderam a trabalhadores contratados no ano em que tinham alguma experiência no emprego formal (reemprego) e mais de 61\% eram remanescentes de contratações de anos anteriores (Tabela 2).

Tabela 2 - Participação e salário/hora médio dos empregados formais no primeiro emprego, reemprego e remanescentes por setor de atividade na região sul do Brasil (2013)

\begin{tabular}{l|c|c|c}
\hline \multicolumn{4}{c}{ Participação } \\
\hline Setor econômico & Primeiro emprego (\%) & Reemprego (\%) & Remanescentes (\%) \\
\hline Agrícola & 3,46 & 3,15 & 3,30 \\
Comércio & 32,56 & 26,50 & 23,19 \\
Serviços & 29,77 & 35,22 & 36,16 \\
Indústria & 34,21 & 35,13 & 37,34 \\
\hline \% & 100,00 & 100,00 & 100,00 \\
\hline Total (\%) & $(339.289)$ & $(2.265 .286)$ & $(4.144 .226)$ \\
\hline Média salário/hora & $\mathbf{5 , 0 3}$ & $\mathbf{3 3 , 5 7 \%}$ & $\mathbf{6 1 , 4 1 \%}$ \\
\hline Setor econômico & Primeiro emprego (R\$) & Reemprego (R\$) & Remanescentes (R\$) \\
\hline Agrícola & 5,70 & 6,30 & 7,59 \\
Comércio & 5,50 & 6,51 & 8,55 \\
Serviços & 8,05 & 8,75 & 14,92 \\
Indústria & 6,19 & 7,45 & 11,45 \\
\hline Geral (R\$) & 6,50 & 7,62 & 11,90 \\
\hline
\end{tabular}

Fonte: Elaborada pelos autores a partir dos microdados da Rais 2013 (BRASIL, 2015).

No que tange à distribuição por setor econômico, a maior parte dos trabalhadores da região que encontrou uma primeira ocupação foi contratada no setor industrial, assim como ocorreu na classe dos remanescentes. Esta tem os maiores salários médios para todos os setores estudados, mas os contratos do primeiro emprego são melhor remunerados no setor de serviços.

A Tabela 3 representa a distribuição na ocupação entre homens e mulheres. Na região em estudo, os homens foram maioria nas ocupações - primeiro emprego, reemprego e remanescentes - e a diferença percentual entre os gêneros é menor para o primeiro emprego. Outros autores como Gonçalves e Monte (2008, 2011) identificam essa realidade para a região nordeste: a contratação pró-homem é menor entre os indivíduos que buscam o primeiro emprego do que entre os indivíduos do reemprego. 


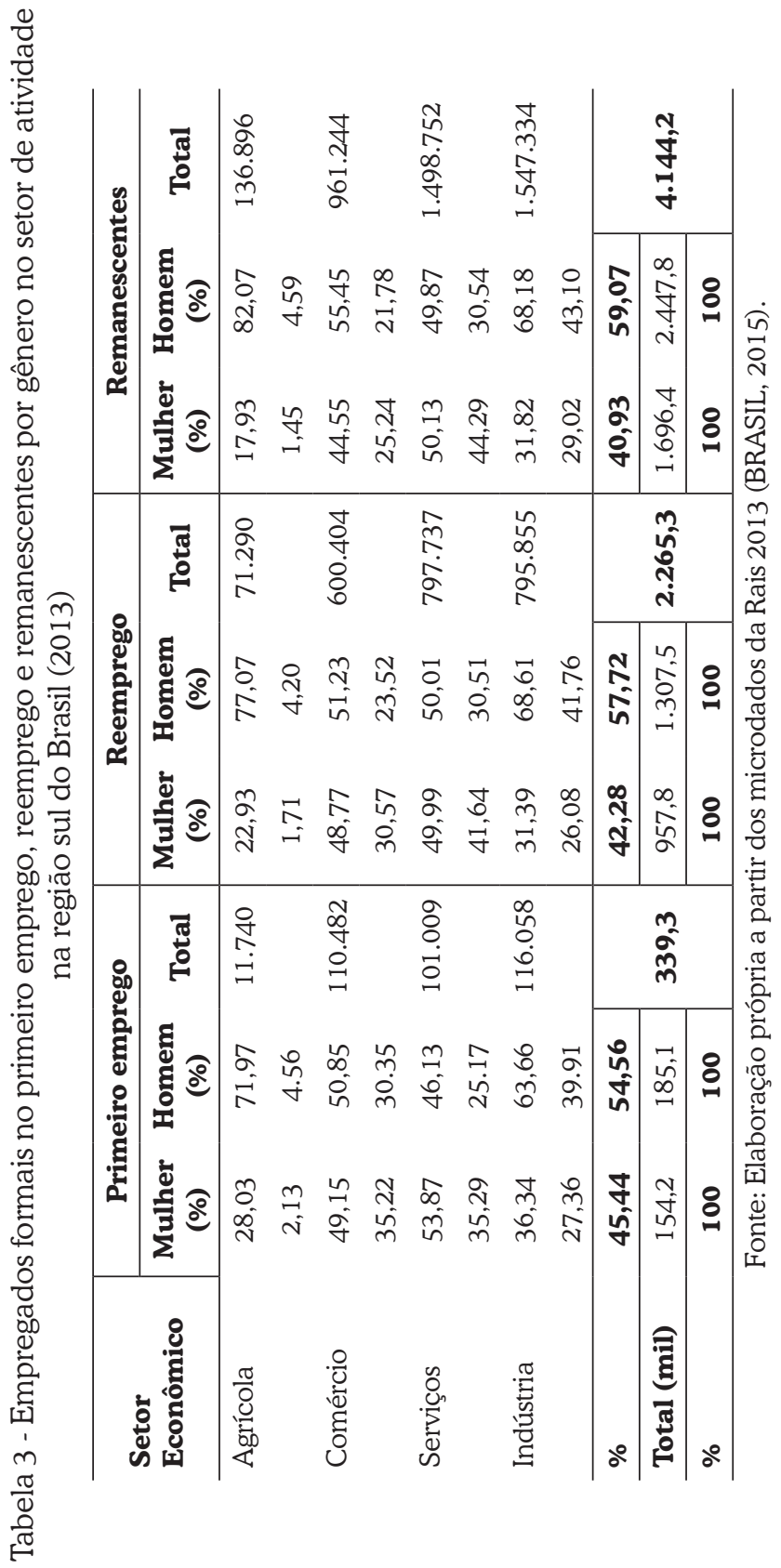


Os setores agrícola e industrial são de características masculinas: do total de contratados na indústria, homens correspondem a 63,66\% para o primeiro emprego e 68,61\% para o reemprego. Para as mulheres, esse percentual é de 36,34\% e 31,39\%, respectivamente. No setor agrícola, essa diferença é ainda maior. Por outro lado, as mulheres são maioria na contratação via primeiro emprego no setor de serviços, aproximadamente $54 \%$. Por fim, o setor de comércio tem uma homogeneidade da distribuição no primeiro emprego e reemprego e uma superioridade masculina nos remanescentes. Dessa forma, os dados relativos apontam um padrão de distribuição dos trabalhadores entre os setores: em cada classe de emprego, os homens são absorvidos relativamente mais na agricultura e na indústria e as mulheres, no comércio e serviços.

$\mathrm{Na}$ análise dos salários horas médios, em geral, os homens apresentam superioridade em relação às mulheres (Tabela 4), e os salários pagos às mulheres e homens no Primeiro emprego são mais homogêneos. Essa análise vai ao encontro dos resultados das pesquisas de Gonçalves e Monte (2008, 2011), os quais constataram que mulheres empregadas no Primeiro emprego tinham uma remuneração média similar à dos homens contratados pela primeira vez, mas os diferenciais salariais a favor dos homens foram maiores na classe do Reemprego do que os observados nas admissões no Primeiro emprego.

No presente estudo, os homens contratados no Primeiro emprego receberam em média 10,17\% mais que as mulheres, e a sua experiência com trabalhos anteriores (reempregados) foi mais valorizada. No geral, a diferença salarial a favor dos indivíduos do sexo masculino foi de $17,71 \%$, a maior diferença salarial entre os sexos está na Indústria e o maior rendimento está no setor de Serviços.

As maiores diferenças salariais de gênero ocorrem entre os trabalhadores Remanescentes, ou seja, entre os trabalhadores que não foram contratados no ano. Nesse caso, o Sul apresentou uma diferença superior a 27\% a favor dos homens, o que pode indicar que a maior parte da diferença salarial contra as mulheres está dentro das empresas; agricultura e indústria tiveram os maiores hiatos salariais a favor dos homens, e a maior diferença no setor da Indústria está na classe de trabalhadores Remanescentes, na qual o diferencial foi superior a $56 \%$ a favor dos homens. 


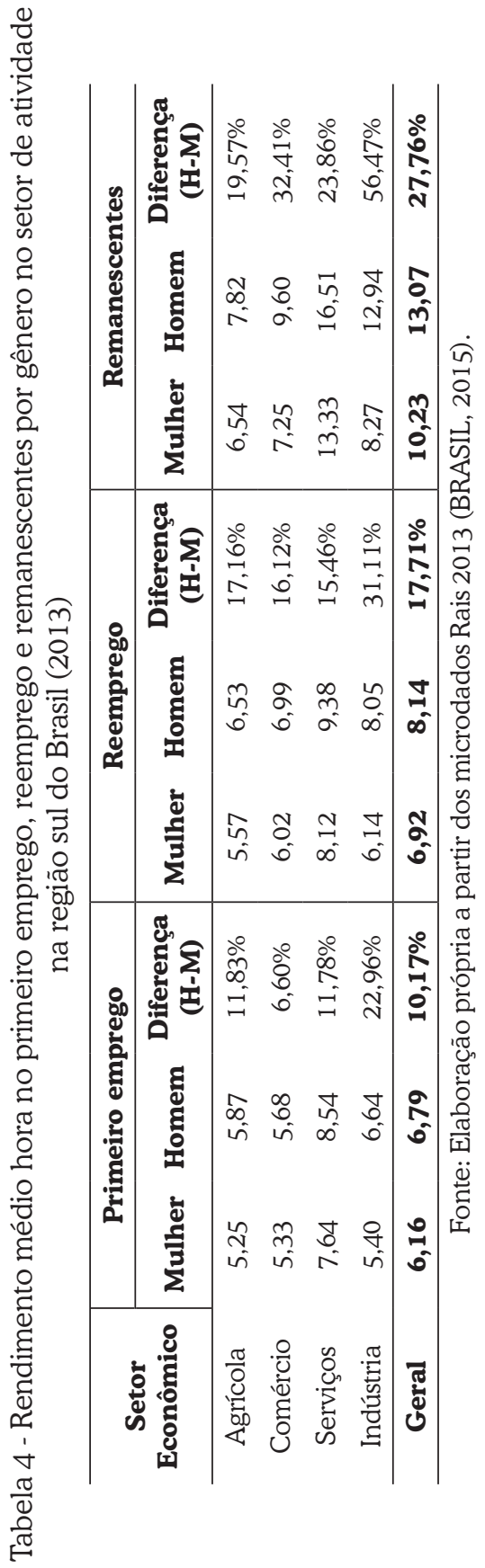


Evidenciadas as diferenças salariais de gênero em favor dos homens, uma parte desse hiato salarial, segundo Babcock et al. (2003), e confirmado por Card, Cardoso e Kline (2013) para o mercado de trabalho português, é decorrente do baixo poder de barganha do sexo feminino. Para as primeiras autoras, as mulheres são em geral menos propensas a iniciar uma negociação almejando um aumento salarial. Outros estudos já elencados no referencial empírico também mostram que a segmentação dos setores, o capital humano e a discriminação salarial e ocupacional podem explicar essas diferenças.

\section{Determinação e Decomposição dos Salários nas Classes de Emprego para Homens e Mulheres na Região Sul}

As equações de determinação de salários estimadas para a região sul nas classes de empregos para cada gênero estão expostas na Tabela 5. Os valores dos coeficientes representam o ganho percentual sobre o salário/hora que um empregado recebe ao acrescentar uma unidade do aspecto em análise - para variáveis contínuas como a experiência -, ou por pertencer a uma classe - para variáveis categóricas como cor, ocupação, faixa de escolaridade etc.

Tabela 5 - Determinantes salariais no primeiro emprego, reemprego e remanescentes na região sul do Brasil (2013)

\begin{tabular}{|c|c|c|c|c|c|c|}
\hline \multirow{2}{*}{ Variável } & \multicolumn{2}{|c|}{ Primeiro emprego } & \multicolumn{2}{|c|}{ Reemprego } & \multicolumn{2}{|c|}{ Remanescentes } \\
\hline & $\mathbf{H}$ & $\mathbf{M}$ & $\mathbf{H}$ & $\mathbf{M}$ & $\mathbf{H}$ & $\mathbf{M}$ \\
\hline Fundamental & $-0,025^{*}$ & $-0,001$ & $0,0882^{*}$ & $0,0436 *$ & $0,1205^{*}$ & $0,0969^{*}$ \\
\hline Médio & $0,1176^{*}$ & $0,0907^{*}$ & $0,1979 *$ & $0,1431 *$ & $0,3112 *$ & $0,2908 *$ \\
\hline Superior & $0,7838^{*}$ & $0,6465^{*}$ & $0,6942 *$ & $0,5558^{*}$ & $1,0236^{*}$ & $0,9370^{*}$ \\
\hline Branco & $0,0278^{*}$ & $0,0334^{*}$ & $0,0317 *$ & $0,0439^{*}$ & $0,0775^{*}$ & $0,0800^{*}$ \\
\hline Experiência & -- & -- & $0,0242 *$ & $0,0107^{*}$ & $0,0346^{*}$ & $0,0190 *$ \\
\hline Experiência2 & -- & -- & $-0,001^{*}$ & $-0,001^{*}$ & $-0,000^{*}$ & $-0,001^{*}$ \\
\hline Dirigentes & $0,4125^{*}$ & $0,2718^{*}$ & $0,4555^{*}$ & $0,3806^{*}$ & $0,5081^{*}$ & $0,4370^{*}$ \\
\hline PCAs & $0,3821^{*}$ & $0,3076^{*}$ & $0,5292 *$ & $0,5307^{*}$ & $0,4213^{*}$ & $0,4203 *$ \\
\hline Técnicos & $0,1071^{*}$ & $0,1089^{*}$ & $0,2101 *$ & $0,2077^{*}$ & $0,2495^{*}$ & $0,2028^{*}$ \\
\hline Pequena & $0,0882^{*}$ & $0,0907^{*}$ & $0,0884 *$ & $0,0823^{*}$ & $0,1872 *$ & $0,1503^{*}$ \\
\hline Média & $0,1256^{*}$ & $0,1416^{*}$ & $0,1512 *$ & $0,1233^{*}$ & $0,3340^{*}$ & $0,2520^{*}$ \\
\hline Grande & $0,1416^{*}$ & $0,1701^{*}$ & $0,1973^{*}$ & $0,1534^{*}$ & $0,4335^{*}$ & $0,3181^{*}$ \\
\hline Outras & $0,1699 *$ & $0,1657^{*}$ & $0,2306^{*}$ & $0,1662^{*}$ & $0,5101 *$ & $0,3671 *$ \\
\hline Comércio & 0,0235 & $0,0675^{*}$ & $0,1580^{*}$ & $0,1263^{*}$ & $0,3298^{*}$ & $0,2088^{*}$ \\
\hline Serviços & $0,1462^{*}$ & $0,1283^{*}$ & $0,1884^{*}$ & $0,1168^{*}$ & $0,3856 *$ & $0,2751 *$ \\
\hline
\end{tabular}


conclusão.

\begin{tabular}{l|cc|cc|c|c}
\hline \multirow{2}{*}{ Variável } & \multicolumn{2}{|c|}{ Primeiro emprego } & \multicolumn{2}{c|}{ Reemprego } & \multicolumn{2}{c}{ Remanescentes } \\
\cline { 2 - 7 } & $\mathbf{H}$ & $\mathbf{M}$ & $\mathbf{H}$ & $\mathbf{M}$ & $\mathbf{H}$ & $\mathbf{M}$ \\
\hline Indústria & $0,1299^{*}$ & $0,0600^{*}$ & $0,2628^{*}$ & $0,1187^{*}$ & $0,4838^{*}$ & $0,2362^{*}$ \\
SC & $0,0464^{*}$ & $0,0473^{*}$ & $0,0209^{*}$ & $0,0432^{*}$ & $0,0218^{*}$ & $0,0550^{*}$ \\
RS & $-0,001$ & $0,0058^{*}$ & $0,0113^{*}$ & $0,0140^{*}$ & $0,0476^{*}$ & $0,0804^{*}$ \\
Constante & $1,4307^{*}$ & $1,3252^{*}$ & $1,1247^{*}$ & $1,2133^{*}$ & $0,6697^{*}$ & $0,8136^{*}$ \\
\hline
\end{tabular}

Fonte: Elaboração própria a partir dos resultados do modelo Log-Lin.

Nota 1: Para minimizar o problema de heterocedasticidade, comum em modelos de determinação de salários, utilizou-se o procedimento de erros robusto de White (1980). Nota 2: Na regressão geral, foi aplicado o teste Chow de quebra estrutural, o que indicou que há possíveis diferenças nos coeficientes entre a regressão dos homens e mulheres. $\mathrm{F}$ (calculado) > F(tabelado), com significância de 1\%. ${ }^{6}$ Nota 3: *Significância de 1\%, * *ignificância de 5\% $\mathrm{e}^{* * *}$ significância de $10 \%$. Os valores apresentados sem asteriscos não foram significativos.

Os resultados apontam que, pertencer a uma faixa educacional mais elevada em relação à faixa de escolaridade omitida (baixa instrução), contribui para um maior salário, independente da classe do emprego e do gênero. $\mathrm{O}$ trabalhador homem, de nível superior e remanescente no mercado de trabalho, tem um ganho salarial de mais de $102 \%$ em comparação com os demais homens de baixa instrução. Todavia, os remanescentes no mercado de trabalho, em geral, têm um retorno de investimento em educação maior em comparação aos indivíduos que foram contratados no ano.

Independente da classe de emprego, a educação e a experiência dos homens foram valoradas de forma superior às das mulheres com as mesmas características não produtivas. Na classe do reemprego, um ano a mais de experiência dos homens gerou retorno salarial de $2,42 \%$ e, para as mulheres, pouco mais de $1 \%$. Essas ocorrências comprovam o esperado pela teoria do capital humano apresentada por Becker (1962, 1966, 2008), Mincer (1958, 1962, 1974) e Schultz (1961) no que se refere às relações entre capital humano e salários, mas também confirma a diferença salarial por sexo, teorizada por Becker (1962) e resenhada por Loureiro (2003).

Os trabalhadores de cor branca também obtiveram retornos positivos (sobre os trabalhadores não brancos) em todas as classes de emprego e gênero: tanto para homens quanto para mulheres, ser da cor branca gerou um ganho salarial de mais de 7\%, e os maiores retornos estão na classe dos remanescentes.

Todos os grupos ocupacionais mostraram retornos positivos sobre a ocupação operacional, para todas as classes de emprego e gênero, sendo os dirigentes e os PCAs os de maiores remunerações. Em destaque, na classe do reemprego, entre

$6 \quad$ Ver Gujarati (2011) e Chow (1960). 
os homens, dirigentes e PCAs, obtêm-se ganhos aproximados de $45,5 \%$ e $53 \%$, respectivamente, sobre o grupo dos trabalhadores operacionais.

No que tange ao tamanho da empresa, quanto maior o empreendimento, maiores serão os salários dos indivíduos em relação aos trabalhadores das microempresas. Esse ganho salarial decorrente do porte da empresa foi superior entre os trabalhadores remanescentes. Além disso, o sexo masculino destaca-se no setor industrial, exibindo maiores retornos positivos sobre o setor omitido (agrícola), especialmente na classe dos remanescentes. Nas regressões femininas, o setor de serviços apresentou o maior percentual de retorno para os remanescentes, $27,51 \%$.

Outros determinantes estão relacionados aos estados da região: ser trabalhador formal em Santa Catarina e Rio Grande do Sul apresenta ganho percentual sobre os salários dos trabalhadores do Paraná. Os contratados no ano têm retornos mais homogêneos, não ultrapassando $5 \%$ em favor dos residentes dos estados em destaque. Finalmente, entre os remanescentes, as mulheres que moram no Rio Grande do Sul apresentam rendimentos 8,04\% maiores do que as trabalhadoras do Paraná.

Em suma, os resultados apontam que as características (produtivas e não produtivas) masculinas são em sua maioria contratadas com salários superiores às dotações (produtivas e não produtivas) femininas. Na comparação entre as classes de emprego, a remuneração das características e as diferenças entre gêneros dos indivíduos remanescentes no mercado de trabalho foram maiores em comparação às classes do primeiro emprego e do reemprego. Isso era esperado, pois esses trabalhadores apresentam, em média, idade mais elevada, maior tempo no emprego (experiência) e maior escolaridade. Assim, de acordo com a teoria do capital humano, essas características podem provocar uma maior produtividade e, consequentemente, um maior salário.

\subsection{Decomposição Salarial nas Classes de Emprego e Setores Econômicos}

Nesta seção estuda-se a decomposição salarial de Oaxaca-Blinder, segundo os setores e classes de emprego. As diferenças salariais foram desagregadas na parcela explicada pelas diferenças das características dos trabalhadores (aspectos produtivos, ocupação e região) e na parcela referente à discriminação de gênero. A base das interpretações foi o salário das mulheres, como nos estudos de Jann (2008), Jones e Kelley (1984) e Blinder (1973).

A parte explicada corresponde ao aumento médio nos salários das mulheres se estas tivessem as mesmas características que os homens. A parte referente à discriminação de gênero corresponde às diferenças dos coeficientes das regressões mincerianas dos homens e mulheres, que quantifica a variação nos salários das mulheres ao aplicar-se os coeficientes dos homens nas características femininas. 
De outra forma, segundo Ehrenberg e Smith (2000), a discriminação no mercado de trabalho ocorre quando trabalhadores com características produtivas idênticas são tratados de forma distinta devido ao grupo demográfico a que pertencem. A discriminação, segundo Blau e Kahn (2000), pode ser maior ou menor em determinadas firmas ou setores. Por essa razão, estudaram-se os setores agrícola, de comércio, de serviços e, por fim, o industrial.

\subsubsection{Setor Agrícola}

Os dados apresentados apontam que o salário/hora médio das mulheres foi inferior ao salário/hora médio dos homens, para todas as classes de emprego, no setor agrícola da região sul. Para que as mulheres tivessem seus salários iguais aos masculinos, seria necessário que os seus rendimentos tivessem um aumento de $10,11 \%, 16,30 \%$ e $18,58 \%$ dos que estão no primeiro emprego, no reemprego e nos remanescentes, respectivamente.

Tabela 6 - Impactos percentuais da discriminação nos salários das mulheres no setor agrícola na região sul do Brasil (2013)

\begin{tabular}{l|c|c|c}
\hline \multicolumn{1}{c|}{ Agricultura } & $\begin{array}{c}\text { Primeiro } \\
\text { emprego }\end{array}$ & Reemprego & Remanescentes \\
\hline Grupos & $5,40^{*}$ & $5,85^{*}$ & $6,80^{*}$ \\
Salário/hora homem (R\$) & $4,91^{*}$ & $5,03^{*}$ & $5,73^{*}$ \\
Salário/hora mulher (R\$) & $\mathbf{- 0 , 6 4 ^ { * * }}$ & $\mathbf{- 0 , 9 8 ^ { * }}$ & $\mathbf{- 3 , 5 2 ^ { * }}$ \\
\hline Diferenças explicadas (\%) & $-0,04$ & $0,06^{*}$ & 0,00 \\
\hline Aspectos raciais & $-0,48^{*}$ & $-0,96^{*}$ & $-2,86^{*}$ \\
Aspectos produtivos & $-0,49^{*}$ & $-0,27^{*}$ & $-0,79^{*}$ \\
Aspectos ocupacionais & $0,37^{*}$ & $0,20^{*}$ & $0,11^{*}$ \\
Aspectos regionais & $\mathbf{1 0 , 8 2 ^ { * }}$ & $\mathbf{1 7 , 4 5 ^ { * }}$ & $\mathbf{2 2 , 9 \mathbf { 1 } ^ { * }}$ \\
\hline Discriminação de gênero (\%) & 2,07 & $-0,17$ & $-1,98^{*}$ \\
\hline Aspectos raciais & $9,40^{*}$ & $17,19^{*}$ & $25,32^{*}$ \\
Aspectos produtivos & $0,86^{*}$ & $0,56^{*}$ & $1,07^{*}$ \\
Aspectos ocupacionais & $-1,60^{*}$ & $-0,17$ & $-0,99^{*}$ \\
Aspectos regionais & $\mathbf{1 0 , 1} *$ & $\mathbf{1 6 , 3 0 *}$ & $\mathbf{1 8 , 5 \mathbf { 1 } ^ { * }}$ \\
\hline Diferença total & &
\end{tabular}

Fonte: Elaboração própria a partir dos resultados da decomposição de Oaxaca-Blinder. Nota: *Significância de 1\%, "*significância de 5\% e * * significância de 10\%. Os valores apresentados sem asteriscos não foram significativos.

A parte das diferenças salariais explicada pelos fatores associados aos aspectos produtivos, à ocupação e região, evidencia o impacto no salário das mulheres 
se elas tivessem as características dos homens, que foi de uma redução de 0,64\% (primeiro emprego), 0,98\% (reemprego) e 3,52\% (remanescentes). Em geral, as características produtivas femininas (escolaridade e experiência) são em média maiores que as masculinas.

A parte não explicada por aqueles fatores (discriminação de gênero) mostra o impacto no salário das mulheres se suas características fossem valoradas de mesma forma que as características masculinas, o que corresponde a um cenário de ausência de discriminação. Nessas condições, o salário das mulheres deveria ter um aumento de $10,82 \%$ (primeiro emprego), $17,45 \%$ (reemprego) e $22,91 \%$ (remanescentes).

Ao subdividir esse efeito da discriminação na região sul, observa-se que o impacto não explicado pelos fatores produtivos foi o que mais contribuiu para a discriminação nas três classes de emprego. Se os aspectos produtivos fossem contratados pelo mesmo valor empregado aos homens, o salário das mulheres deveria ter um aumento de 9,40\% (primeiro emprego), 17,19 (reemprego) e 25,32 (remanescentes). Em relação aos aspectos raciais, esta pesquisa apontou que, entre os remanescentes, a discriminação de cor de pele é maior entre as mulheres do que entre os homens, o que agrava a situação das mulheres negras.

Os resultados apresentados na Tabela 7 correspondem às decomposições salariais de Oaxaca-Blinder entre os brancos e os não brancos. No setor agrícola, entre os trabalhadores brancos, o salário/hora médio das mulheres foi inferior ao salário/hora médio dos homens, em todas as classes de emprego. Para que as mulheres tivessem seus salários iguais aos masculinos, seria necessário que os seus rendimentos tivessem um aumento de 10,56\% (primeiro emprego), 16,15\% (reemprego) e $17,68 \%$ (remanescentes). 
Tabela 7 - Impactos percentuais da discriminação nos salários das mulheres brancas e não brancas no setor agrícola na região sul do Brasil (2013)

\begin{tabular}{|c|c|c|c|}
\hline \multirow[b]{2}{*}{ Agricultura } & \multicolumn{3}{|c|}{ Brancos } \\
\hline & $\begin{array}{l}\text { Primeiro } \\
\text { emprego }\end{array}$ & Reemprego & Remanescentes \\
\hline \multicolumn{4}{|l|}{ Grupos } \\
\hline Salário/hora homem $(\mathrm{R} \$)$ & $5,45^{*}$ & $5,90^{*}$ & $6,85^{*}$ \\
\hline Salário/hora mulher $(\mathrm{R} \$)$ & $4,93^{*}$ & $5,08^{*}$ & $5,82^{*}$ \\
\hline Diferenças explicadas (\%) & $-0,69^{*}$ & $-1,21^{*}$ & $-3,95^{*}$ \\
\hline Discriminação de gênero (\%) & $11,33^{*}$ & $17,57^{*}$ & $22,51^{*}$ \\
\hline \multirow[t]{2}{*}{ Diferença total } & $10,56^{*}$ & $16,15^{*}$ & $17,68^{*}$ \\
\hline & \multicolumn{3}{|c|}{ Não brancos } \\
\hline Salário/hora homem $(\mathrm{R} \$)$ & $5,18^{*}$ & $5,63^{*}$ & $6,50 *$ \\
\hline Salário/hora mulher $(\mathrm{R} \$)$ & $4,79^{*}$ & $4,84^{*}$ & $5,24^{*}$ \\
\hline Diferenças explicadas (\%) & 0,24 & $-0,07$ & $-0,97^{*}$ \\
\hline Discriminação de gênero (\%) & $7,80 *$ & $16,53^{*}$ & $25,46^{*}$ \\
\hline Diferença total & $8,06 *$ & $16,45^{*}$ & $24,24^{*}$ \\
\hline
\end{tabular}

Fonte: Elaboração própria a partir dos resultados da decomposição de Oaxaca-Blinder.

Nota: *Significância de 1\%, * *significância de 5\% e * * significância de 10\%. Os valores apresentados sem asteriscos não foram significativos.

Caso as mulheres tivessem as mesmas características dos homens, observariam uma redução em seus rendimentos de 0,69\%, 1,21\% e 3,95\% nas classes de primeiro emprego, reemprego e remanescentes, respectivamente. Na ausência de discriminação de sexo, o salário das mulheres deveria ter um aumento de 11,33\% (primeiro emprego), 17,57\% (reemprego) e 22,51\% (remanescentes). O impacto não explicado pelos fatores produtivos foi o que mais contribuiu para a discriminação nas três classes de emprego: 11,61\% (primeiro emprego), 17,05 (reemprego) e 22,53 (remanescentes).

$\mathrm{Na}$ comparação entre os não brancos, a predominância do salário/hora médio foi masculina, independente da classe de emprego. Com exceção dos remanescentes, a discriminação de gênero é menor entres os trabalhadores não brancos. Entretanto, em relação à magnitude dos percentuais, não houve grandes divergências nos resultados da discriminação salarial de brancos e não brancos, apontando que, para o setor agrícola, a discriminação de gênero independe da cor de pele. 


\subsubsection{Setor de Comércio}

Os dados da Tabela 8 mostram que, no setor de comércio, os salários/hora médios das mulheres foram inferiores aos salários/hora médios dos homens, para todas as classes de emprego. Para que as mulheres tivessem seus salários iguais aos masculinos, seus rendimentos deveriam ter um aumento de 4,01\% (primeiro emprego), 12,71\% (reemprego) e 23,97\% (remanescentes).

Tabela 8 - Impactos percentuais da discriminação nos salários das mulheres no setor de comércio na região sul do Brasil (2013)

\begin{tabular}{l|c|c|c}
\hline \multicolumn{1}{c|}{ Comércio } & $\begin{array}{c}\text { Primeiro } \\
\text { emprego }\end{array}$ & Reemprego & Remanescentes \\
\hline Grupos & $5,25^{*}$ & $6,37^{*}$ & $8,00^{*}$ \\
Salário/hora homem (R\$) & $5,05^{*}$ & $5,65^{*}$ & $6,45^{*}$ \\
Salário/hora mulher (R\$) & $\mathbf{- 1 , 6 7 ^ { * }}$ & $\mathbf{- 0 , 1 7 ^ { * }}$ & $\mathbf{0 , 9 9 *}$ \\
\hline Diferenças explicadas (\%) & $-0,01$ & $-0,05^{*}$ & $-0,04^{*}$ \\
\hline Aspectos raciais & $-1,79^{*}$ & $-0,78^{*}$ & $-1,07^{*}$ \\
Aspectos produtivos & $-0,16^{*}$ & 0,04 & $0,41^{*}$ \\
Aspectos ocupacionais & $0,24^{*}$ & $0,55^{*}$ & $1,71^{*}$ \\
Porte da empresa & $0,05^{*}$ & $0,08^{*}$ & $-0,01$ \\
Aspectos regionais & $\mathbf{5 , 7 7 ^ { * }}$ & $\mathbf{1 2 , 9 1 ^ { * }}$ & $\mathbf{2 2 , 7 5 ^ { * }}$ \\
\hline Discriminação de gênero (\%) & $-0,25$ & $1,93^{*}$ & $0,88^{*}$ \\
\hline Aspectos raciais & $5,40^{*}$ & $6,97^{*}$ & $13,44^{*}$ \\
Aspectos produtivos & $0,17^{*}$ & $0,15^{*}$ & $0,51^{*}$ \\
Aspectos ocupacionais & $-0,01$ & $3,09^{*}$ & $6,81^{*}$ \\
Porte da empresa & $0,45^{*}$ & $0,29^{*}$ & $-0,08$ \\
Aspectos regionais & $\mathbf{4 , 0 1 *}$ & $\mathbf{1 2 , 7 1 ^ { * }}$ & $\mathbf{2 3 , 9 7 ^ { * }}$ \\
\hline Diferença total & & & \\
\hline
\end{tabular}

Fonte: Elaboração própria a partir dos resultados da decomposição de Oaxaca-Blinder.

Nota: *Significância de 1\%, "*significância de 5\% e ** *ignificância de 10\%. Os valores apresentados sem asteriscos não foram significativos.

Apesar da significância estatística, os valores referentes à parcela explicada pelos aspectos tratados não foram representativos. A maior parte da explicação do diferencial salarial entre os gêneros origina-se da discriminação, ou seja, na ausência de discriminação, o salário das mulheres deveria aumentar em 5,77\% (primeiro emprego), 12,91\% (reemprego) e 22,75\% (remanescentes).

No setor de comércio, os fatores produtivos (escolaridade e experiência) e o porte das empresas foram os que mais contribuíram para a discriminação de 
gênero. Por exemplo, na classe dos remanescentes, se os aspectos produtivos das mulheres fossem precificados igualmente aos dos homens, os salários delas aumentariam em mais de 13\%. Em relação ao porte da empresa, para essa classe de emprego, o percentual pago a mais para os trabalhadores masculinos de empresas maiores em comparação às microempresas foi superior ao percentual pago para as mulheres. Caso o percentual pago a mais aos homens pelas empresas (de pequeno, médio e grande porte) em relação às microempresas fosse atribuído às mulheres, seus rendimentos teriam um aumento de $6,81 \%$.

Em relação aos aspectos raciais, o resultado, apesar da baixa representatividade percentual, apontou que no setor de comércio a discriminação de cor de pele é maior entre os homens, agravando a situação do homem negro. Esse resultado reforça a preferência desse setor pelo trabalhador do sexo feminino.

Tabela 9 - Impactos percentuais da discriminação nos salários das mulheres brancas e não brancas no setor de comércio na região sul do Brasil (2013)

\begin{tabular}{|c|c|c|c|}
\hline \multirow[b]{2}{*}{ Comércio } & \multicolumn{3}{|c|}{ Brancos } \\
\hline & $\begin{array}{l}\text { Primeiro } \\
\text { emprego }\end{array}$ & Reemprego & Remanescentes \\
\hline \multicolumn{4}{|l|}{ Grupos } \\
\hline Salário/hora homem $(\mathrm{R} \$)$ & $5,27^{*}$ & $6,41 *$ & $8,06^{*}$ \\
\hline Salário/hora mulher $(\mathrm{R} \$)$ & $5,06^{*}$ & $5,68^{*}$ & $6,49 *$ \\
\hline Diferenças explicadas (\%) & $-1,65^{*}$ & $-0,08$ & $1,22 *$ \\
\hline Discriminação de gênero (\%) & $5,89 *$ & $13,07^{*}$ & $22,59 *$ \\
\hline \multirow[t]{2}{*}{ Diferença total } & $4,14^{*}$ & $12,98^{*}$ & $24,09 *$ \\
\hline & \multicolumn{3}{|c|}{ Não brancos } \\
\hline Salário/hora homem $(\mathrm{R} \$)$ & $5,11^{*}$ & $6,00^{*}$ & $7,40^{*}$ \\
\hline Salário/hora mulher $(\mathrm{R} \$)$ & $4,95^{*}$ & $5,40 *$ & $6,00^{*}$ \\
\hline Diferenças explicadas (\%) & $-1,40^{*}$ & 0,02 & $-0,15$ \\
\hline Discriminação de gênero (\%) & $4,72 *$ & $11,16 *$ & $23,56 *$ \\
\hline Diferença total & $3,25^{*}$ & $11,17^{*}$ & $23,38^{*}$ \\
\hline
\end{tabular}

Fonte: Elaboração própria a partir dos resultados da decomposição de Oaxaca-Blinder.

Nota: "Significância de 1\%, "*significância de 5\% e **"significância de 10\%. Os valores apresentados sem asteriscos não foram significativos.

A Tabela 9 mostra que, entre os brancos, os salários das mulheres foram inferiores ao dos homens para todas as classes de emprego: 4,14\% (primeiro emprego), $12,98 \%$ (reemprego) e $24,09 \%$ (remanescentes). A maior parte desse diferencial salarial contra as mulheres foi decorrente da discriminação de gênero. Na ausência de discriminação, os salários das mulheres teriam um incremento de 5,89\% (primeiro emprego), 13,07\% (reemprego) e 22,59\% (remanescentes). Ademais, as 
diferenças de salários foram menores para os não brancos do que para os brancos, independente das classes de emprego. Com exceção da classe dos remanescentes, o percentual discriminatório contra as mulheres foi menor entre os não brancos.

\subsubsection{Setor de Serviços}

O salário/hora médio das mulheres foi inferior ao dos homens no setor de serviços para as classes de primeiro emprego, reemprego e remanescentes. Para que as mulheres tivessem seus salários iguais aos masculinos, seria necessário que seus salários tivessem um aumento de 10,55\%, 16,84\% e 22,54\%, respectivamente, conforme a Tabela 10.

Tabela 10 - Impactos percentuais da discriminação nos salários das mulheres no setor de serviços na região sul do Brasil (2013)

\begin{tabular}{|c|c|c|c|}
\hline Serviços & $\begin{array}{l}\text { Primeiro } \\
\text { emprego }\end{array}$ & Reemprego & Remanescentes \\
\hline \multicolumn{4}{|l|}{ Grupos } \\
\hline Salário/hora homem $(\mathrm{R} \$)$ & $6,66^{*}$ & $7,47^{*}$ & $11,19^{*}$ \\
\hline Salário/hora mulher $(\mathrm{R} \$)$ & $6,02 *$ & $6,39 *$ & $9,13^{*}$ \\
\hline Diferenças explicadas (\%) & $-4,00^{*}$ & $-4,40^{*}$ & $-5,58^{*}$ \\
\hline Aspectos raciais & $-0,15^{*}$ & $-0,13^{*}$ & $-0,11^{*}$ \\
\hline Aspectos produtivos & $-4,21 *$ & $-2,68^{*}$ & $-5,01 *$ \\
\hline Aspectos ocupacionais & $-0,87^{*}$ & $-2,26 *$ & $-2,27^{*}$ \\
\hline Porte da empresa & $1,26^{*}$ & $0,64^{*}$ & $1,91 *$ \\
\hline Aspectos regionais & $-0,02$ & 0,001 & $-0,10^{*}$ \\
\hline Discriminação de gênero (\%) & $15,16^{*}$ & $22,21 *$ & 29,79* \\
\hline Aspectos raciais & $2,91 *$ & 0,38 & $-2,33^{*}$ \\
\hline Aspectos produtivos & $13,33^{*}$ & $24,66^{*}$ & $31,25^{*}$ \\
\hline Aspectos ocupacionais & $0,68 * *$ & $-0,41 *$ & 0,11 \\
\hline Porte da empresa & $-0,57$ & 0,38 & $5,64^{*}$ \\
\hline Aspectos regionais & $-1,37^{*}$ & $-2,32^{*}$ & $-4,27^{*}$ \\
\hline Diferença total & $10,55^{*}$ & $16,84^{*}$ & $22,54 *$ \\
\hline
\end{tabular}

Fonte: Elaboração própria a partir dos resultados da decomposição de Oaxaca-Blinder.

Nota: "Significância de 1\%, "*significância de 5\% e ** "significância de 10\%. Os valores apresentados sem asteriscos não foram significativos.

A parte explicada pelos aspectos descritos na Tabela 10 comprova o impacto no salário das mulheres se estas tivessem as características dos homens, pois nesse caso o salário médio das mulheres se reduziria em $4 \%$ (primeiro emprego), 4,4\% (reemprego) e 5,58\% (remanescentes). Por outro lado, se as características femini- 
nas fossem valoradas de mesma forma que as masculinas, o salário das mulheres deveria ter um incremento de 15,16\% (primeiro emprego), 22,21\% (reemprego) e $29,79 \%$ (remanescentes). Os aspectos produtivos e o porte das empresas foram os que mais contribuíram para isso.

A Tabela 11 reúne os dados da decomposição salarial para as os indivíduos de cor de pele branca e não branca no setor de serviços. O salário/hora médio das mulheres brancas foi inferior ao dos homens brancos para todas as classes de emprego. O salário médio das mulheres sofreria uma redução de 3,94\% (primeiro emprego), 4,51\% (reemprego) e 5,46\% (remanescentes) caso elas tivessem as características dos homens. Na ausência de discriminação, o salário das mulheres aumentaria em 15,66\% (primeiro emprego), 22,20\% (reemprego) e 29,44\% (remanescentes).

Tabela 11 - Impactos percentuais da discriminação nos salários das mulheres brancas e não brancas no setor de serviços na região sul do Brasil (2013)

\begin{tabular}{l|c|c|c}
\hline \multirow{2}{*}{ Serviços } & \multicolumn{3}{c}{ Brancos } \\
\cline { 2 - 4 } & $\begin{array}{c}\text { Primeiro } \\
\text { emprego }\end{array}$ & Reemprego & Remanescentes \\
\hline Grupos & & & \\
Salário/hora homem (R\$) & $6,81^{*}$ & $7,59^{*}$ & $11,40^{*}$ \\
Salário/hora mulher (R\$) & $6,13^{*}$ & $6,50^{*}$ & $9,32^{*}$ \\
\hline Diferenças explicadas (\%) & $\mathbf{- 3 , 9 4 *}$ & $\mathbf{- 4 , 5 1 *}$ & $\mathbf{- 5 , 4 6 *}$ \\
\hline Discriminação de gênero (\%) & $\mathbf{1 5 , 6 6 *}$ & $\mathbf{2 2 , 2 0 *}$ & $\mathbf{2 9 , 4 4 ^ { * }}$ \\
\hline Diferença total & $\mathbf{1 1 , 1 1 ^ { * }}$ & $\mathbf{1 6 , 6 9 *}$ & $\mathbf{2 2 , 3 8 ^ { * }}$ \\
\hline & & $\mathbf{N a ̃ o} \mathbf{b r a n c o s}$ & \\
\hline Salário/hora homem (R\$) & $5,82^{*}$ & $6,79^{*}$ & $9,42^{*}$ \\
Salário/hora mulher (R\$) & $5,33^{*}$ & $5,65^{*}$ & $7,26^{*}$ \\
\hline Diferenças explicadas (\%) & $\mathbf{- 2 , 2 7 *}$ & $\mathbf{- 1 , 4 5 *}$ & $\mathbf{- 3 , 0 9 *}$ \\
\hline Discriminação de gênero (\%) & $\mathbf{1 1 , 6 6 *}$ & $\mathbf{2 2 , 0 1 *}$ & $\mathbf{3 3 , 9 1 *}$ \\
\hline Diferença total & $\mathbf{9 , 1 2 *}$ & $\mathbf{2 0 , 2 4 *}$ & $\mathbf{2 9 , 7 7 ^ { * }}$ \\
\hline
\end{tabular}

Fonte: Elaboração própria a partir dos resultados da decomposição de Oaxaca-Blinder.

Nota: *Significância de 1\%, "*significância de 5\% e * * significância de 10\%. Os valores apresentados sem asteriscos não foram significativos.

Para os indivíduos não brancos, independente da classe de emprego e gênero, o salário/hora médio é menor quando comparado aos dos brancos. No sul, na classe do primeiro emprego, a diferença de rendimentos entre homens e mulheres e a discriminação é menor entre os não brancos. Para o reemprego, a diferença salarial de gênero foi menor entre os brancos, porém apresentou uma maior discriminação contra a mulher. Já entre os remanescentes, tanto as diferenças salariais 
entre homens e mulheres quanto a discriminação de gênero foram maiores entre os não brancos.

\subsubsection{Setor de Indústria}

Os dados da Tabela 12 exibem as evidências para a Indústria. Neste setor, o salário hora médio das mulheres foi inferior ao dos homens. Para que a mulheres tivessem igualdade seus salários teriam que aumentar 15,59\% (Primeiro emprego), 25,44\% (Reemprego) e 46,35\% (Remanescentes). E mais, caso as trabalhadoras tivessem as características dos homens, os salários das mulheres sofreriam uma redução de 2,25\% no Primeiro emprego e de 3,27\% para a classe do Reemprego. Para a classe dos Remanescentes, as características dos trabalhadores, em média, são equivalentes entre homens e mulheres, uma vez que se fossem observadas as mesmas características masculinas nas mulheres, os salários delas sofreriam um aumento de apenas 0,2\%.

Tabela 12 - Impactos percentuais da discriminação nos salários das mulheres no setor de indústria na região sul do Brasil (2013)

\begin{tabular}{l|c|c|c}
\hline \multicolumn{1}{c|}{ Indústria } & $\begin{array}{c}\text { Primeiro } \\
\text { emprego }\end{array}$ & Reemprego & Remanescentes \\
\hline Grupos & $5,88^{*}$ & $7,11^{*}$ & $10,21^{*}$ \\
Salário/hora homem (R\$) & $5,09^{*}$ & $5,67^{*}$ & $6,98^{*}$ \\
Salário/hora mulher (R\$) & $\mathbf{- 2 , 2 5 *}$ & $\mathbf{- 3 , 2 7 *}$ & $\mathbf{0 , 2 0 *}$ \\
\hline Diferenças explicadas (\%) & 0,00 & $-0,01$ & $-0,16^{*}$ \\
\hline Aspectos raciais & $-1,07^{*}$ & $-1,55^{*}$ & $0,17^{*}$ \\
Aspectos produtivos & $-0,22^{*}$ & $-0,69^{*}$ & $0,28^{*}$ \\
Aspectos ocupacionais & $-0,86^{*}$ & $-1,05^{*}$ & $-0,02$ \\
Porte da empresa & $-0,11^{*}$ & $-0,01^{* *}$ & $-0,08^{*}$ \\
Aspectos regionais & $\mathbf{1 8 , 2 6 *}$ & $\mathbf{2 9 , 6 \mathbf { 6 } ^ { * }}$ & $\mathbf{4 6 , 0 6 *}$ \\
\hline Discriminação de gênero (\%) & $-2,13^{*}$ & $-2,41^{*}$ & $1,10^{*}$ \\
\hline Aspectos raciais & $17,76^{*}$ & $26,87^{*}$ & $29,44^{*}$ \\
Aspectos produtivos & $0,39^{*}$ & $0,60^{*}$ & $0,53^{*}$ \\
Aspectos ocupacionais & $1,82^{*}$ & $4,62^{*}$ & $12,08^{*}$ \\
Porte da empresa & 0,38 & $-0,47^{*}$ & $-0,94^{*}$ \\
Aspectos regionais & $\mathbf{1 5 , 5 9 *}$ & $\mathbf{2 5 , 4 4 ^ { * }}$ & $\mathbf{4 6 , 3 5 ^ { * }}$ \\
\hline Diferença total & & & \\
\hline
\end{tabular}

Fonte: Elaboração própria a partir dos resultados da decomposição de Oaxaca-Blinder. Nota: *Significância de 1\%, "*significância de 5\% e ***significância de 10\%. Os valores apresentados sem asteriscos não foram significativos. 
Ainda em relação aos salários, estes teriam um incremento de $18,26 \%$ (primeiro emprego), 29,68\% (reemprego) e 46,06\% (remanescentes) na ausência de discriminação de gênero. Esses percentuais são atribuídos quase exclusivamente aos fatores produtivos e ao porte das empresas na classe dos remanescentes.

Heinze e Wolf (2006) defendem que as empresas desempenham um papel importante na criação e manutenção da desigualdade de gênero, pela forma como definem a contratação e as recompensas. A constatação de que na classe dos remanescentes estão os maiores salários, independente do setor econômico, e as maiores diferenças salariais e discriminação contra as mulheres vão ao encontro dos resultados de Albrecht, Van Vuuren e Vroman (2004), que observam maiores diferenças salariais entre homens e mulheres para quantias mais elevadas de renda.

Os dados da Tabela 13 apresentam a decomposição salarial para os trabalhadores de cor de pele branca e não branca. Independente da classe de emprego, as mulheres estão em desvantagem quando observado o salário, sendo que na classe dos remanescentes essa diferença é superior a $46 \%$.

Tabela 13 - Impactos percentuais da discriminação nos salários das mulheres brancas no setor de indústria na região sul do Brasil (2013)

\begin{tabular}{|c|c|c|c|}
\hline \multirow[b]{2}{*}{ Indústria } & \multicolumn{3}{|c|}{ Brancos } \\
\hline & $\begin{array}{l}\text { Primeiro } \\
\text { emprego }\end{array}$ & Reemprego & Remanescentes \\
\hline \multicolumn{4}{|l|}{ Grupos } \\
\hline Salário/hora homem (R\$) & $5,91 *$ & $7,12^{*}$ & $10,38^{*}$ \\
\hline Salário/hora mulher $(\mathrm{R} \$)$ & $5,12 *$ & $5,70 *$ & $7,07^{*}$ \\
\hline Diferenças explicadas (\%) & $-2,32^{*}$ & $-3,34^{*}$ & $0,59 * *$ \\
\hline Discriminação de gênero (\%) & $18,22 *$ & $29,17^{*}$ & $45,93 *$ \\
\hline \multirow[t]{2}{*}{ Diferença total } & $15,48^{*}$ & $24,85^{*}$ & $46,79^{*}$ \\
\hline & \multicolumn{3}{|c|}{ Não brancos } \\
\hline Salário/hora homem $(\mathrm{R} \$)$ & $5,74^{*}$ & $7,05^{*}$ & $8,90 *$ \\
\hline Salário/hora mulher $(\mathrm{R} \$)$ & $4,90 *$ & $5,40^{*}$ & $6,09 *$ \\
\hline Diferenças explicadas (\%) & $-0,98^{*}$ & $-2,10^{*}$ & $-0,34^{*}$ \\
\hline Discriminação de gênero (\%) & $18,35^{*}$ & $33,43 *$ & $46,68^{*}$ \\
\hline Diferença total & $17,19^{*}$ & $30,63^{*}$ & $46,17^{*}$ \\
\hline
\end{tabular}

Fonte: Elaboração própria a partir dos resultados da decomposição de Oaxaca-Blinder. Nota: "Significância de 1\%, " "significância de $5 \%$ e ** "significância de 10\%. Os valores apresentados sem asteriscos não foram significativos.

Pela parte explicada, o impacto no salário das mulheres caso tivessem as características dos homens seria de uma redução de pouco mais de 3\% (reemprego), 
aproximadamente 2,3\% (primeiro emprego) e menos de $1 \%$ (remanescentes). $\mathrm{Na}$ ausência de discriminação, o salário das mulheres aumentaria em 18,22\% (primeiro emprego), $29,17 \%$ (reemprego) e 45,93\% (remanescentes).

Para os indivíduos não brancos, independente da classe de emprego ou gênero, o salário/hora médio é menor quando comparado ao salário/hora dos brancos. Entre os gêneros, as mulheres tiveram menores salários/hora do que os homens, para todas as classes de emprego. Tanto as diferenças de rendimentos do trabalho assalariado quanto a discriminação de gênero foram maiores entre os indivíduos não brancos do que entre os brancos.

Outro destaque é que as diferenças salariais contra as mulheres na indústria podem ser atribuídas, quase em sua totalidade, à discriminação de gênero. No primeiro emprego e no reemprego, as diferenças explicadas pelas dotações produtivas dos postos de trabalho e pela raça amenizam a diferença salarial total, e, nos remanescentes, aqueles fatores se somam à discriminação, aumentando o diferencial de salários. Fiuza-Moura (2015) encontra um percentual de 41,87\% de discriminação contra as mulheres para a indústria no Brasil, com base na PNAD de 2012.

Uma das possíveis origens dessa discriminação salarial pode estar relacionada, segundo Becker (1971), com a discriminação do empregado. Assim, os homens do setor de indústria podem estar evitando situações que tenham que interagir com as mulheres. Mesmo que não haja preconceito por parte do empregador, este tem de pagar um prêmio (salários maiores) para esses funcionários se submeterem a tal interação.

Em suma, confirmam-se a existência das diferenças salariais e da discriminação de gênero na região sul do Brasil da mesma forma que os estudos de Pereira e Oliveira (2016), baseado no Censo de 2010 para o Rio Grande do Sul, e de Cacciamali, Tatei e Rosalino (2009) em relação ao Brasil como um todo. Estes constatam, utilizando dados da PNAD de 2006, que houve um hiato de 33\% entre o salário observado e o salário a ser recebido na ausência de discriminação para as mulheres em 2006.

Heinze e Wolf (2006) argumentam que as empresas desempenham um papel importante na criação e manutenção da desigualdade de gênero pela forma como definem a contratação e recompensas. Além disso, as diferenças do salário/ hora entre os gêneros e a discriminação contra o sexo feminino são menores quando verificados os contratados pela primeira vez (primeiro emprego) e maiores entre os remanescentes, o que pode indicar que a discriminação contra as mulheres se agrava dentro das empresas. ${ }^{7}$ Esses resultados mostram similaridades ao estudo de Souza e Gomes (2015) para o estado da Bahia.

$7 \quad$ Na pesquisa não foi incorporada a decisão da oferta de trabalho feminina em virtude das características da base de dados utilizada, essencialmente da demanda de trabalho. 
As evidências deste trabalho também vão ao encontro das verificadas por Cacciamali e Hirata (2005), Salvato et al. (2008) e Albrecht, Van Vuuren e Vroman (2004), cujas diferenças e discriminação salarial foram maiores para faixas de renda ou grupos que obtiveram maiores rendimentos. Nesse estudo, tanto as diferenças quanto a discriminação salarial foram superiores nas classes de emprego e nos setores econômicos em que os trabalhadores obtiveram os maiores rendimentos. Por fim, confere-se procedência ao fato de que a região sul, desenvolvida economicamente, tende a reservar significativo nível de desigualdade salarial, pois, conforme Lovell (1993 apud LOUREIRO, 2003), a discriminação é mais acentuada em regiões mais desenvolvidas no Brasil.

\section{Considerações Finais}

Este estudo teve como objetivo analisar as diferenças salariais e a discriminação de gênero segundo os setores e as classes de emprego para a região sul do Brasil em 2013. Os resultados apontaram retornos positivos para as variáveis do capital humano (escolaridade e experiência), sendo maiores para os trabalhadores remanescentes e menores para a classe do primeiro emprego, independente do setor econômico. $\mathrm{O}$ fato de o indivíduo ser homem gerou os maiores retornos na comparação com as mulheres, independente do setor econômico. Possuir cor de pele branca suscitou ganhos salariais sobre aqueles cuja pele é de cor parda ou negra, e esses ganhos mostraram-se maiores nos setores de comércio e de serviços e entre os remanescentes.

As ocupações de dirigentes, PCAs e técnicos também tiveram ganhos de salário sobre a ocupação de trabalhadores operacionais, porém o comportamento foi distinto se considerados os diferentes setores econômicos e classes de emprego. Quanto ao porte das empresas, os resultados são de que, quanto maior o tamanho do empreendimento, melhores são as remunerações atribuídas pelas empresas, especialmente para os remanescentes. Assim, as diferenças salariais provenientes das ocupações, porte das empresas e setores econômicos foram justificadas pela teoria da segmentação.

Esta pesquisa também indicou que uma maior discriminação contra as mulheres ocorreu entre os remanescentes e a menor discriminação, no primeiro emprego, o que mostra que, a despeito da não incorporação das modificações da oferta de trabalho na pesquisa realizada, a discriminação contra as mulheres pode se manifestar, com o passar do tempo, dentro da empresa. O setor industrial efetiva a maior discriminação contra as mulheres, que se agrava entre os remanescentes. Todavia, o setor que apresentou os menores percentuais de discriminação contra as mulheres foi o setor de comércio, sendo menor ainda quando analisado no primeiro emprego. 
Apesar de identificadas as origens setoriais e de classe de emprego das desigualdades de salário, seu tratamento é complexo. Segundo a Organização Internacional do Trabalho (OIT), para se alcançar a igualdade salarial é necessário se superar a visão de que as mulheres têm menor necessidade de renda do que os homens, de que são uma força de trabalho secundária, de que os homens estão no mercado de forma mais permanente e de que a presença das mulheres no mercado de trabalho é algo recente.

Algumas medidas para minimizar a desigualdade salarial de gênero e minorias no curto e médio prazo poderiam incluir o estímulo às negociações coletivas dos salários, porque, segundo Babcock et al. (2003), as mulheres são inibidas a negociarem melhores salários, além da intensificação da ação das políticas públicas e da fiscalização contra a discriminação econômica das mulheres, defendidas tanto pela Constituição Federal de 1988 quanto pela Declaração Universal dos Direitos Humanos.

As evidências deste estudo em relação às diferenças e discriminação salarial de gênero nos setores econômicos, em especial no comércio (menor discriminação salarial contra as mulheres) e na indústria (maior discriminação contra as mulheres), assim como a sua incidência entre os remanescentes no mercado de trabalho, podem contribuir para uma intervenção pública e privada mais eficiente na região estudada. Os achados dessa investigação potencializam novos estudos para se compreender melhor a distribuição dos trabalhadores nas ocupações para cada setor econômico e, assim, analisar-se as diferenças de salários e discriminação de gênero nas classes de emprego.

\section{Referências}

ALBRECHT, J.; VAN VUUREN, A.; VROMAN, S. Decomposing the gender wage gap in the Netherlands with sample selection adjustments. Bonn, Germany, 2004. (IZA Discussion Paper Series n. 1400). Disponível em: < http://papers.ssrn.com/sol3/papers.cfm?abstract_ $\mathrm{id}=621064>$. Acesso em: 04 jun. 2015.

ARROW, K. The theory of discrimination. Princeton, NJ, US: Princeton University, 1971. (Working Paper n. 30A). Disponível em: < https://dataspace.princeton.edu/jspui/ bitstream/88435/dsp014t64gn18f/1/30a.pdf > . Acesso em: 18 jun. 2105.

BABCOCK, L. et al. Nice girls don't ask. Harvard Business Review, Boston, MA, US, v. 81, n. 10, p. 14-16, Oct. 2003.

BATISTA, N. N.; CACCIAMALI, M. C. Diferencial de salários entre homens e mulheres segundo a condição de migração. Revista Brasileira de Estudos de População, Rio de Janeiro, v. 26, n. 1, p. 97-115, jan./jun. 2009.

BECKER, G. S. Human capital. Library of Economics and Liberty. Carmel, IN, US, [2008]. Disponível em: < http://www.econlib.org/library/Enc/HumanCapital.html > . Acesso em: 18 jun. 2015. 
. Investment in human capital: a theoretical analysis. Journal of Political Economy, Chicago, IL, US, v. 70, n. 5, p. 9-49, 1962. Press, 1975.

. The economics of discrimination. 2. ed. Chicago, IL, US: The University of Chicago

; CHISWICK, B. R. Education and the distribution of earnings. American Economic Review, v. 56, n. 2, p. 358-369, 1966.

BLAU, F. D.; KAHN, L. M. Gender differences in pay. Journal of Economic Perspectives, v. 14, n. 4, p. 75-99, 2000.

BLINDER, A. S. Wage discrimination: reduced form and structural estimates. The Journal of Human Resources, v. 8, n. 4, 1973.

BRASIL. Ministério do Trabalho e Emprego. Dados e estatísticas: Relação Anual de Informações Sociais. Brasília, 2013. Disponível em: < http://www3.mte.gov.br/rais/default. asp>. Acesso em: 11 abr. 2015.

CACCIAMALI, M. C. S. Mercado de trabalho: abordagens duais. Revista de Administração de Empresas, São Paulo, v. 18, n. 1, p. 59-69, 1978.

; HIRATA, G. I. A influência da raça e do gênero nas oportunidades de obtenção de renda: uma análise da discriminação em mercados de trabalho distintos: Bahia e São Paulo. Estudos Econômicos, São Paulo, v. 35, n. 4, p. 767-795, out./dez. 2005.

; TATEI, F.; ROSALINO, J. W. Estreitamento dos diferenciais de salários e aumento do

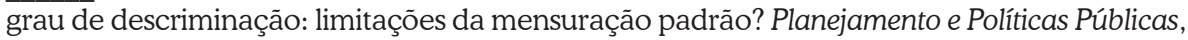
Brasília, n. 33, p. 195-222, 2009.

CARD, D.; CARDOSO, A. R.; KLINE, P. Bargaining and the gender wage gap: a direct assessment, Institute for the Study of Labor (IZA), August, 2013, 69p.

CASARI, P. Segmentação no mercado de trabalho brasileiro: diferenças entre o setor agropecuário e os setores não agropecuários, período de 2004 a 2009. 2012. 139 f. Tese (Doutorado em Economia Aplicada) - Universidade de São Paulo, Escola Superior de Agricultura "Luiz de Queiroz", Piracicaba, 2012.

CHAHAD, J. P. Z. O mercado de trabalho no Brasil: aspectos teóricos e evidências empíricas. São Paulo: IPEA/USP, 1986.

CHOW, G. C. Tests of equality between sets of coefficients in two linear regressions. Econometrica, v. 28, n. 3, p. 591-605, July, 1960.

CUGINI, S. C. B. et al. A força de trabalho feminina no mercado de trabalho brasileiro: discriminação salarial por gênero em 2002 e 2011. In: ENCONTRO DE ECONOMIA PARANAENSE, 11., 2014, Apucarana. Anais... Apucarana: Unespar, 2014. 19 p.

DICKINSON, D.; OAXACA, R. Statistical discrimination in labor markets: an experimental analysis. Bonn, Germany, 2006. (IZA Discussion Papers Series n. 2305). Disponível em: $<$ http://papers.ssrn.com/sol3/papers.cfm?abstract_id=933035>. Acesso em: 4 jun. 2015. 
DOERINGER, P.; PIORE, M. Internal labor markets and manpower analysis. Washington, DC, US, May 1970. Disponível em: < https://files.eric.ed.gov/fulltext/ED048457.pdf > . Acesso em: 4 jun. 2015.

EHRENBERG, R.; SMITH, R. A moderna economia do trabalho: teoria e política. São Paulo: Makron Books, 2000.

FIUZA-MOURA, F. K. Diferenciais de salário na indústria brasileira por sexo, cor e intensidade tecnológica. 2015. 96 f. Dissertação (Mestrado em Economia Regional) - Universidade Estadual de Londrina, Londrina, 2015.

GOMES, M. R. et al. Probabilidade do primeiro emprego nos setores econômicos: uma análise no estado de Santa Catarina. In: ENCONTRO DE ECONOMIA CATARINENSE: POLÍTICAS PÚBLICAS E DESENVOLVIMENTO REGIONAL, 9., 2015, Chapecó. Anais... Chapecó: Unochapecó, 2015. 18 p.

GONÇALVES, M. F.; MONTE, P. A. Admissão por primeiro emprego e reemprego no mercado formal do nordeste: um estudo mesorregional. In: ENCONTRO NACIONAL DE ESTUDOS POPULACIONAIS, 16., 2008, Caxambu. Anais... Caxambu: UFMG, 2008. 17 p.

; __ _ . A importância da experiência profissional na admissão e na disparidade salarial: um estudo para o mercado de trabalho formal do nordeste. Economia $e$ Desenvolvimento, Recife, v. 10, n. 1, p. 131-168, 2011.

GREENE, W. H. Econometric analysis. 7. ed. Upper Saddle River, NJ, US: Prentice Hall, 2012.

GUJARATI, D. N. Econometria básica. 4. ed. Rio de Janeiro: Campus, 2006.

HARRISON, B.; SUM, A. The theory of "dual" or segmented labor markets. Journal of Economic Issues, v. 13, n. 3 p. 687-706, 1979.

JANN, B. The Blinder-Oaxaca decomposition for linear regression models. The Stata Journal, v. 8, n. 4, p. 453-479, May 2008.

LIMA, R. Mercado de trabalho: o capital humano e a teoria da segmentação. Pesquisa e Planejamento Econômico, Rio de Janeiro, v. 10, n. 1, p. 217-272, 1980.

LOUREIRO, P. R. A. Uma resenha teórica e empírica sobre economia da discriminação. Revista Brasileira de Economia, Rio de Janeiro, v. 57, n. 1, p. 125-157, 2003.

MARGONATO, R. C. G.; SOUZA, S. C. I. Trabalho feminino: perfil ocupacional por gênero e setores econômicos na região sul do Brasil e Santa Catarina. In: ENCONTRO DE ECONOMIA CATARINENSE, 5., 2011, Florianópolis. Anais... Florianópolis: Unesc, 2011. 19 p.

MINCER, J. Investment in human capital and personal income distribution. Journal of Political Economy, v. 66, n. 4, p. 281-302, 1958.

. On-the-job training: costs, returns and some implications. Journal of Political Economy, v. 70, n. 5, p. 50-79, 1962.

. Schooling, experience and earnings. New York: National Bureau of Economic $\overline{\text { Research, } 1974 .}$ 
MONTE, P. A. Inserção ocupacional e duração de desemprego nas regiões metropolitanas do Brasil: primeiro emprego e reemprego. 2005. 126 f. Tese (Doutorado em Economia) Universidade Federal de Pernambuco, Recife, 2005.

; ARAÚJO, T. P.; LIMA, R. A. Primeiro emprego e reemprego: análise de inserção ocupacional e duração do desemprego no Brasil metropolitano. Economia e Desenvolvimento, Recife, v. 7, n. 1, p. 139-177, 2007.

OAXACA, R. Male-female wage differentials in urban labor markets. International Economic Review, v. 14, n. 3, p. 693-709, Oct. 1973.

PEREIRA, R. M.; OLIVEIRA, C. A. Os diferenciais de salário por gênero no Rio Grande do Sul: uma aplicação do modelo de Heckman e da decomposição de Oaxaca-Blinder. Redes: Revista do Desenvolvimento Regional, Santa Cruz do Sul, RS, v. 21, n. 1, p. 148-173, 2016.

PHELPS, E. S. The statistical theory of racism and sexism. The American Economic Review, v. 62, n. 4, p. 659-661, Sept. 1972.

ROCHA, S. A inserção dos jovens no mercado de trabalho. Caderno CRH, Salvador, v. 21, n. 54, p. 533-550, set./dez. 2008.

SALVATO, M. A. et al. Mercado de trabalho em Minas Gerais e Bahia: considerações sobre uma análise da discriminação de raça e gênero. In: SEMINÁRIO SOBRE A ECONOMIA MINEIRA, 13., 2008, Belo Horizonte. Anais... Belo Horizonte: UFMG, 2008. 23 p.

SERVIÇO BRASILEIRO DE APOIO ÀS MICRO E PEQUENAS EMPRESAS. Anuário do trabalho na micro e pequena empresa: 2013. 6. ed. Brasília, DF: Dieese, 2013.

SCHULTZ, T. W. Investment in human capital. American Economic Review, v. 51, n. 1, p. 1-17, Mar. 1961.

SOUZA, P. F. L. A importância da discriminação nas diferenças salariais: uma análise para o Brasil e suas regiões para os anos de 2002, 2006 e 2009. 2011. 115 f. Dissertação (Mestrado em Economia) - Universidade Federal do Ceará, Fortaleza, 2011.

SOUZA, S. D. C. I.; GOMES, M. R. Diferenças salariais de gênero no primeiro emprego dos trabalhadores: análise no estado da Bahia em 2013. In: ENCONTRO DE ECONOMIA BAIANA, 9., 2015, Salvador. Anais... Salvador: FIEB, 2015. 19 p.

VIETORISZ, T.; HARRISON, B. Labor market segmentation: positive feedback and divergent development. American Economic Review, v. 63, n. 2, p. 366-376, May 1973.

WHITE, H. A heteroskedasticity-consistent covariance matrix estimator and direct test for heteroskedasticity. Econometrica, v. 48, n. 4, p. 817-838, May 1980.

YUN, M. A simple solution to the identification problem in detailed wage decompositions. New Orleans: Tulane University, 2003. (IZA Discussion Paper Series n. 836).

Recebido em: 28/10/2016. Aceito em: 13/02/2017. 